\title{
Reptile species persistence under climate change and direct human threats in north-western Argentina
}

\author{
JAVIER NORI*1, GERARDO C. LEYNAUD ${ }^{1}$, JOSÉ VOLANTE ${ }^{2}$, CRISTIAN S. ABDALA ${ }^{3}$, \\ GUSTAVO J. SCROCCHI ${ }^{3}$, CLARITA RODRÍGUEZ-SOTO ${ }^{4}$, ROBERT L. PRESSEY ${ }^{5}$ AND \\ RAFAEL LOYOLA ${ }^{6,7}$ \\ ${ }^{I}$ Centro de Zoología Aplicada and Instituto de Diversidad y Ecología Animal (CONICET), Universidad Nacional de Córdoba, Córdoba, \\ Argentina, ${ }^{2}$ Laboratorio de Teledetección y SIG, Instituto Nacional de Tecnología Agropecuaria (INTA), Estación Experimental Agropecuaria \\ Salta. Ruta Nacional 68, Km 172 Cerrillos, Salta, Argentina, ${ }^{3}$ UEL Unidad Ejecutora Lillo, Conicet, FML - Universidad Nacional de Tucumán, \\ Argentina, ${ }^{4}$ Centro de Estudios e Investigación en Desarrollo Sustentable. Universidad Autónoma del Estado de México, Toluca, México, ${ }^{5}$ Australian \\ Research Council Centre of Excellence for Coral Reef Studies, Fames Cook University, Tomnsville, Queensland 4811, Australia, ${ }^{6}$ Laboratório de \\ Biogeografia da Conservação, Departamento de Ecologia, Universidade Federal de Goiás, Brazil and ${ }^{7}$ Brazilian Research Netmork on Climate \\ Change - Rede Clima, Instituto Nacional de Pesquisas Espaciais, São José dos Campos, São Paulo, Brazil
}

Date submitted: 6 October 2016; Date accepted: 24 April 2017

\section{SUMMARY}

Protected areas have been established historically in residual places where the potential for extractive uses is low, implying that places at risk are usually underprotected. Argentina is no exception, with few protected areas established in productive regions that are prone to conversion. Here, using reptiles as a study group and considering the most important human threats in north-western Argentina, we estimated priority conservation areas where we expect species to persist in the face of climate change and land conversion. Protected areas cover no more than $9 \%$ of the study region, but represent less than $15 \%$ of reptile distributions. There are great opportunities for improving the conservation status in the region by protecting only $8 \%$ more of north-western Argentina, with the level of species protection inside the protected area network increasing almost four-fold, reaching $43 \%$ of species distributions on average and $59 \%$ of the distributions of threatened reptiles. Fortunately, the highest diversity of reptiles in the region does not match the places targeted for agriculture expansion. Our findings suggest that future prioritization schemes should embrace other groups that are especially diverse in the Chaco ecoregion, which overlaps with our study area.

Keymords: agriculture expansion, land-use change, species distribution models, systematic conservation planning, threatened species

\section{INTRODUCTION}

The human population is growing and will continue to grow at the expense of natural resources (Balmford et al.

\footnotetext{
*Correspondence: Dr Javier Nori email: javiernori@gmail.com Supplementary material can be found online at https://doi. org/10.1017/S0376892917000285
}

2012). Inevitably, this trend affects all types of ecosystems, causing habitat loss, biological invasions, pollution and overexploitation of natural resources. These changes in turn lead to species extinctions and a loss of the ecosystem services that species provide (Pimm \& Raven 2000; Hoffman et al. 2010; Laurance et al. 2012; Pimm et al. 2014).

Extinctions are also caused by the general tendency for protected areas (PAs) to be established all around the globe without giving enough importance to species' distributions or their ecological needs. More specifically, PAs are typically located in residual places where the potential for extractive uses is low (Pressey et al. 2015). The dominantly residual nature of PAs is one reason why species continue to go extinct, even when most countries have increased the number and extent of established PAs over the past 10 years (Watson et al. 2014). Such PA networks are not capable of properly representing biodiversity (see Rodrigues et al. 2004, 2014; Venter et al. 2014; Nori \& Loyola 2015; Nori et al. 2015, 2016a), and in fact tend to represent the species and ecosystems least in need of conservation intervention (Pressey et al. 2015). In addition, the effectiveness of established PAs strongly depends on their management, which is highly variable among countries (Mascia et al. 2014; Watson et al. 2014).

Due to the relative ineffectiveness of existing PAs, the identification of priority areas for nature conservation has become extremely important (Margules \& Pressey 2000; Kremen et al. 2008; Loyola et al. 2012). To address these challenges, different conservation planning schemes have been developed over the last decade (e.g. Ciarleglio et al. 2008, 2009; Sarkar \& Illoldi-Rangel 2010; Moilanen et al. 2014). Conservation planning helps to identify the most important sites for conservation by considering the most serious threats to biodiversity, such as the effects of global climate change on species distributions (e.g. Carroll et al. 2010; Groves et al. 2012; Loyola et al. 2012). Conservation planning also helps to reconcile conservation with human activities, such as by minimizing conservation requirements in those areas that are most suitable for agricultural practices. Nevertheless, 
in several countries, conservation decision makers do not take advantage of these techniques, leading to suboptimal conservation decisions with consequent inefficient use of funds and continued exposure of species to threats.

Argentina is one of these countries where the advances in conservation planning have not yet been absorbed into policy. Consequently, the most unproductive regions of the country, such as the Puna or Andean ecoregions, hold a large number of PAs, while productive ecoregions, such as the Chaco or Pampas ecoregions, have only a few small, isolated PAs located in the areas least suitable for extractive uses (see Fig. S1, available online; Burkart 2006; Nori et al. 2013; IUCN \& UNEP 2015; Nori et al. 2016a) with strong management problems (Burkart 2006; DeFries et al. 2010). Administration of PAs in Argentina is divided into six political regions, with north-western Argentina (NWA) being one of the most important and diverse. The region has five federal provinces, covering an area of $470,000 \mathrm{~km}^{2}$ and five ecoregions (sensu Olson et al. 2001; for details, see Appendix S1). NWA also displays a residual pattern of $\mathrm{PA}$ establishment; in fact, the Chaco portion of NWA has one of the highest deforestation rates in the world while having only $5 \%$ of the PAs established in the region (Grau \& Gasparri 2009; Hoyos et al. 2013; Grau et al. 2015; Nori et al. 2016a). In contrast, most PAs in NWA are located in the Puna ecoregion, an extensive but extremely unproductive plain located at more than $3500 \mathrm{~m}$ of altitude.

Among vertebrates, reptiles are very diverse in NWA, with not only a large number of species $(n=138$; almost $40 \%$ of all reptiles in the country), but also high levels of endemism (Abdala et al. 2012; Giraudo et al. 2012; Szumik et al. 2012). Additionally, reptiles are rather homogeneously distributed in the region, with at a least five species inhabiting each ecoregion (Abdala et al. 2012). In this sense, it is expected that reptiles could represent a good focal group for the selection of priority conservation areas in NWA. However, it is also important to consider that the pattern of reptile species richness could be incongruent with the patterns exhibited for other vertebrates (Powney et al. 2010). Furthermore, reptiles are generally among the vertebrates that are most threatened by global climate change (Sinervo et al. 2010) and agricultural practices (Gibbons et al. 2000). Particularly in NWA, reptiles are highly exposed to climate change (Nori et al. 2016b) and/or threatened by land-use changes (Torres et al. 2014).

There is a clear need for well-informed decisions to support the conservation of species and ecosystems in NWA. The aim of this paper is to determine priority areas for conservation in NWA, considering the potential effects of climate change and regional land-use changes on the distribution of reptile species in the region.

\section{MATERIALS AND METHODS}

\section{Study area}

The north-west region of Argentina comprises five political provinces (Catamarca, Jujuy, Salta, Santiago del Estero and Tucumán). The study area is described in Appendix S1.

\section{Species' occurrence records and distributions}

Most species' records (83\%) were obtained from the herpetological collection of the Fundación Miguel Lillo and field trips conducted by the authors between 2012 and 2014. We complemented our database with records from herpetological collections of the Universidad Nacional de Salta, Museo Argentino de Ciencias Naturales and relevant literature. We compiled 2692 occurrence records for 102 species of reptiles (Table S1 and Table S2). These species correspond to $81 \%$ of the total number of lizards and snakes occurring in NWA, including $89 \%$ of the reptiles classified as threatened or data deficient in the region (Abdala et al. 2012; Giraudo et al. 2012).

Considering the amount of data and the characteristics of each species' occurrences, distributional ranges were included in land prioritization models in three different ways. First, we were able to generate species distribution models (SDMs) in order to characterize the ranges of 51 species. This methodology was applied only for the species that met the following criteria: (1) having at least 15 independent occurrence records; (2) not marginally distributed in NWA (see Thuiller et al. 2004); and (3) with distribution models of high performance (true skill statistic $>0.7$ ) in at least one repetition (see 'Species distribution models' section for details). Second, the distributions of 27 species (most of them microendemic), for which the number of records was not sufficient to generate SDMs, were characterized based on a minimum convex polygon performed with the available information. All of these distributions were supervised and validated by recognized experts of each taxonomic group. Third, for the remaining 24 species that, on the advice of experts, had too few records to generate minimum convex polygons, we used raw records in the prioritization, with the Species of Special Interest feature of Zonation software (for details, see Moilanen et al. 2014 and Table S2).

\section{Climatic data}

We used 20 variables for both current and future climate conditions (available from www.worldclim.org for present conditions). Environmental data were at a spatial resolution of 0.5 arc minutes $(c .1 \mathrm{~km})$. We conducted a pairwise Pearson correlation between all of the climatic variables and then selected five of them for which we did not detect strong collinearity (retaining those with $r<0.75$ ). We retained the following variables: diurnal range in temperature, temperature seasonality, temperature annual range, mean temperature of warmest quarter, precipitation of warmest quarter and altitude. These variables were downloaded at present and future hypothetical conditions (year 2050). Given the uncertainties associated with SDMs (Diniz-Filho et al. 2009), we selected three global circulation models (INMCM4, 
CCSM4 and GFDL-CM3) for the concentration trajectory Representative Concentration Pathways (RCP) 4.5 of the year 2050. All of these models were included in the last report of the Intergovernmental Panel on Climate Change (www.ipcc.ch/report/ar5/).

\section{Species distribution models}

SDMs sought to establish statistical relationships between environmental variables and species presence. The models were calibrated with current climate variables and then projected to the same variables in order to estimate the potential distributions of species under current climatic conditions (Franklin 2009). The same models were also projected to the same variables under future scenarios in order to study the geographic responses of the species to climate change (Ladle \& Whittaker 2011).

Since alternative SDM methods have different levels of accuracy under different circumstances and there is no single 'best' method (Araújo \& New 2007), we combined two different algorithms into an ensemble model. We used surface range envelope (SRE; Busby 1991) and MaxEnt (Phillips et al. 2006) to model species' distributions, firstly because they have been indicated to be accurate approaches when working with presence-only datasets (i.e. without real absence data of species; Varela et al. 2014), and secondly, because we needed a standardized approach in order to model many sets of records with different characteristics (e.g. varying numbers and densities of records), we decided to include a very simple envelope method (SRE) and a complex learning machine method (MaxEnt) in the ensemble in order to combine the insights from methods of different complexities (Rangel \& Loyola 2012; Merow et al. 2014). We built all of the models using biomod2 (Thuiller et al. 2013).

We randomly divided the data for each species into $75 \%$ of records for model calibration and 25\% for model evaluation. We weighed pseudo-absences in order to achieve a prevalence of 0.5. The definition of the calibration area has important implications in model calibration and evaluation (Barve et al. 2011), so we decided to generate pseudo-absences more than $10 \mathrm{~km}$ and no more than $2000 \mathrm{~km}$ away from the presences in order to minimize the inclusion of pseudo-absences in areas that are not accessible by the species. To evaluate model performance, we calculated sensitivity and specificity based on the probability threshold for which their sum is maximized. Then, we calculated the true skill statistic in order to assess the performance of each model (Liu et al. 2011).

We ran the models for each method (and each species) three times, each time using different sets of pseudo-absences and random sets of $75 \%$ of the presences. Then, each model was projected into four different climate scenarios (i.e. current conditions and the three future scenarios for the year 2050). A total of six projections were generated for each species for current time models (two algorithms for SDMs, one current climate scenario and three replicates), and a total of 18 projections were generated for each species for future climate scenarios (two algorithms for SDMs, three global circulation models and three replicates; $2 \times 3 \times 3=18$ ). Finally, for each species, we grouped all projections and generated final ensembles as a weighted mean of those projections (six for the present and 18 for the future) with true skills statistics $>0.7$. Final ensembles for each species - one for current and one for future conditions - were converted into binary maps using the maximum value of suitability as the threshold, which accepts an omission rate of $10 \%$ at current conditions. We selected a threshold based on a fixed omission rate because our SDMs were built from presence-only data.

\section{Definition of priority areas for conservation}

We used Zonation 4.0.0b to identify priority areas for the conservation of reptiles in NWA (Moilanen et al. 2014). Zonation software established a hierarchical prioritization of areas of the study region, allowing for the identification of the most important areas for the conservation of species based on their distributions and different cost variables. We ran our analyses using the Additive Benefit Function of Zonation, which assigns conservation values to each cell based on the sum of weighted occurrences of all species (for details, see Di Minin et al. 2014).

We assigned weights for species based on their conservation status (Abadala et al. 2012; Giraudo et al. 2012) as follows: 1 for species assigned as least concern (LC), 1.5 (i.e. $50 \%$ more weight) for those assigned as vulnerable (VU) and data deficient (DD); and 2 (i.e. 100\% more weight) for endangered (EN) species. No species is currently classified as critically endangered (CR). Given the low suitability of reptiles in highly modified areas, we assigned negative weights to areas currently occupied by: (a) crops, (b) human populations and (c) mining and oil extraction activities. This prevented the software from assigning high conservation values to those areas.

In order to determine areas occupied by crops, we used a detailed map of the current land use of the study area and generated a binary raster, discriminating pixels with more than $70 \%$ of their area covered by crops in 2011 (see Fig. S1, current crops; for more details, see Volante et al. 2016). We also incorporated a continuous raster of human population densities from http://neo.sci.gsfc.nasa.gov/ (Schneider et al. 2009). Mining and oil extraction sites in the study area were identified from the Instituto Geográfico Nacional Argentino (IGN). First, we generated vector maps containing all of the available sites for mines and oil wells listed by the IGN (see http://www.ign.gob.ar/sig - file 'Actividades Humanas'). From this vector file, we were able to generate a continuous raster (varying between 0 and 1) containing the density of these sites in a $20-\mathrm{km}$ radius of each pixel. We assigned negative weights to these features in a way such that the sum of the positive and negative weighted features was zero, allowing for a balanced solution in the prioritization (Moilanen et al. 2011; Faleiro \& Loyola 2013). All of the variables were used at a spatial resolution of $0.5 \mathrm{arc}$ minutes. 
Given that climate and land-use changes determine species distributions (Garcia et al. 2014), we incorporated the potential effect of climate change on species' distributions in a conservative way, using both current and future potential distributions for the identification of priority areas for conservation. To develop this scenario, we used the Interaction File function in Zonation in order to give high conservation priority to those cells in which species are predicted to be present under both current and future climates (for details, see Faleiro et al. 2013; Lemes \& Loyola 2013). Future potential distributions were only considered for those (51) species for which we were able to build SDMs. We reclassified our final prioritization into binary maps showing the top $17 \%$ and $25 \%$ priority cells in NWA (the first threshold was that suggested in Aichi Targets; CBI 2010; Woodley et al. 2012). We then calculated species representations for each threshold, considering: (a) all species and (b) only threatened (VU and EN) and DD species.

\section{RESULTS}

A total of 182 projections (60\% of all models, $84 \%$ from MaxEnt and $40 \%$ from SRE) had values for the true skills statistic higher than 0.7 and were included in the final ensembles. Model ensembles were therefore built upon models with relatively accurate projections. These projections had average values of the true skills statistic of 0.88 for MaxEnt models and 0.84 for SRE models (see final binary maps for current and future condition in Appendix S2).

Geographically, priority areas for conservation (considering the top $17 \%$ of the territory) cover a large portion of the central-north and central-south of NWA (Fig. 1). These areas are within the Yungas (29\% of the priority areas) and Monte ecoregions (39\% of the priority areas) and are mainly located in transition zones with the Gran Chaco ecoregion (12\% of the priority areas). A total of $14 \%$ of the Puna ecoregion was also represented in priority areas. Only $5 \%$ of the priority areas are located in the Andean Steppe ecoregion.

Already-established PAs cover 9\% of NWA and are mainly located in the Puna ecoregion (64\% of the protected surface of the study area), with only $5 \%$ of the PAs located in the Chaco ecoregion. PAs represent, on average, $15 \%$ of the distributions of all species (more than $55 \%$ of the species with less than $5 \%$ of their distributions represented) and $22 \%$ of the distributions of threatened (VU and EN) and DD species (Fig. 2).

Considering our prioritization, by protecting an additional $8 \%$ of the territory, the average representation of PAs would increase considerably, covering on average $43 \%$ of species distributions (with only $11 \%$ of the species with less than $10 \%$ of their distributions represented and $20 \%$ of the species with less than a quarter of their distributions represented) and $58 \%$ of threatened (VU and EN) and DD species distributions (Fig. 2). When the highest $25 \%$ priority of the territory is selected, the average representation is $57 \%$ considering all species and $69 \%$ for threatened (VU and EN) and DD species (Fig. 2).

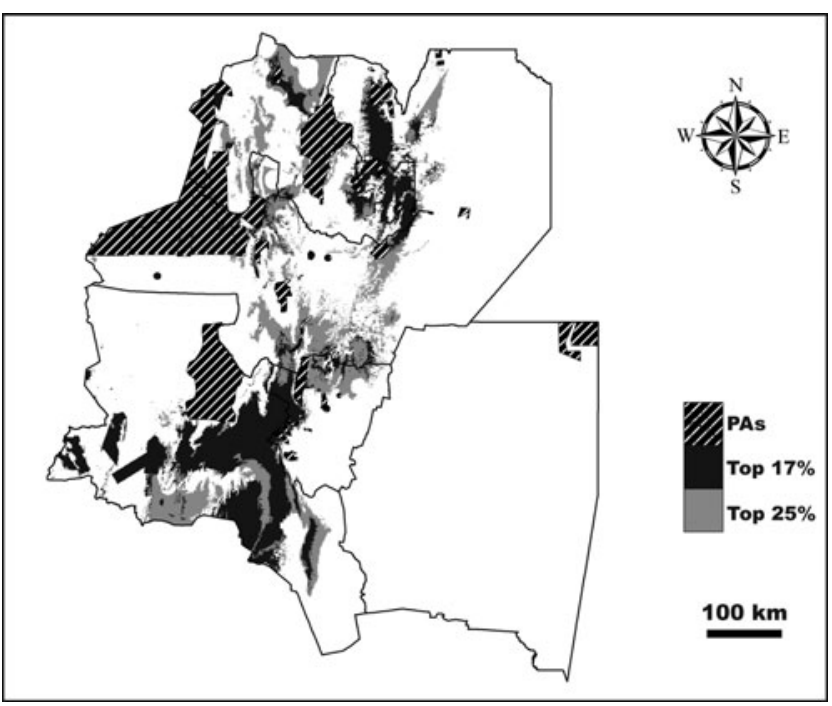

Figure 1 Maps of the current protected areas of the region (striped) and potential expansion areas identified in our spatial prioritization scheme. Dark grey areas correspond to the best $17 \%$ of the region (including already-established PAs) for investing in conservation actions. Light grey areas correspond to priority areas ranging from the best $17 \%$ to the best $25 \%$ of the region. Black lines are the limits of the five political provinces of north-western Argentina. $\mathrm{PA}=$ protected area.

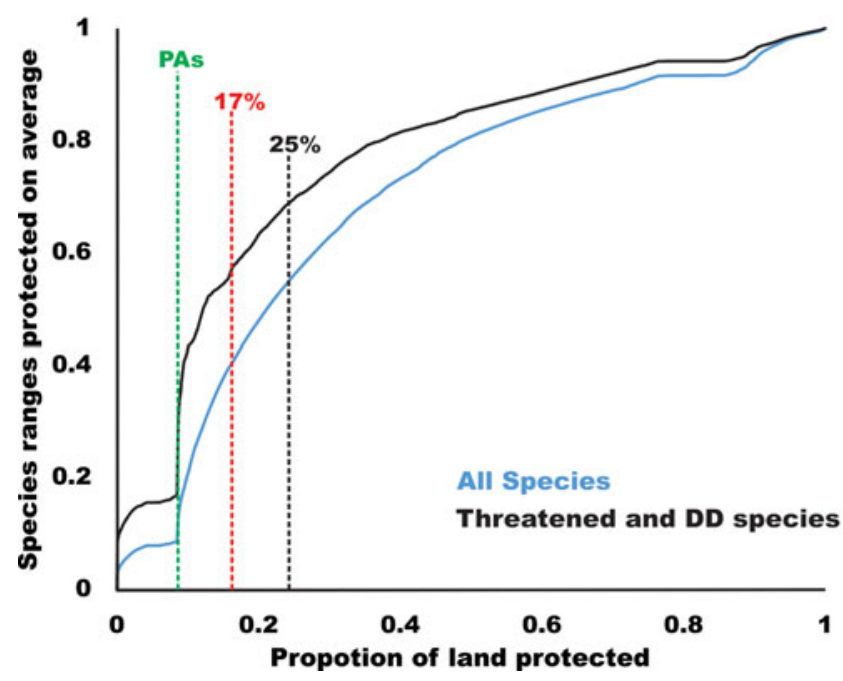

Figure 2 Performance curves of our spatial prioritization scheme, showing the proportions of available grid cells that are protected and their corresponding representations, considering all species together, and only threatened species and DD species. DD = data deficient; $\mathrm{PA}=$ protected area.

\section{DISCUSSION}

This is the first study in Argentina to identify priority areas for conservation considering human modifications to land cover and the potential effect of global climate change on species distributions. Worryingly, PAs in NWA repeat the common pattern reported over recent years (e.g. Pressey et al. 2002; Devillers et al. 2015), characterized by a biased protection of 
environments, with substantial under-representation of the most threatened areas in productive regions (Pressey et al. 2015).

The low equitability in the representation of the different environments of the region is perhaps one of the reasons our results identified a very poor representation of reptile species in existing PAs. In fact, with $9 \%$ of the territory falling inside existing PAs, average representation of species distributions is only $15 \%$, with most of them very poorly represented (less than $5 \%$ of their distributions for most of the species). However, it would be possible to represent more species (along with higher percentages of their geographic distributions) with just an $8 \%$ increase in protection; this would elevate average species representation fourfold.

Most priority areas are located in the Yungas and Monte ecoregions. The larger parts of these ecoregions are not suitable for intensive agriculture, although mining, extraction of oil and wood and extensive livestock grazing threaten species in these ecoregions (Brown et al. 2006). In general, these activities do not require large proportions of land (in the case of mining and oil extraction) and do not generate great changes in land cover (in the case of extensive grazing and selective logging), leading to less conflict between human development and conservation than that observed in areas under intensive production.

Given its great potential for agriculture, priority areas in the Gran Chaco ecoregion and its transition zones with the Yungas and Monte ecoregions are the most vulnerable. Deforestation rates in these regions are among the highest worldwide (Hoyos et al. 2013; Frate et al. 2015). Conservation actions in these priority areas are urgently needed, given that, as time passes, conservation possibilities will drastically decrease (Fuller $\mathrm{et} \mathrm{al}$. 2007; Nori et al. 2013).

In some of the present ecoregions that are poorly influenced by extractive activities, such as Monte or Puna, the number of species is exceptionally high for reptiles compared to other terrestrial vertebrates groups, such as mammals or birds. The pattern is the opposite in the Gran Chaco (i.e. lower reptile species richness than for other vertebrate groups; e.g. birds), which is the most threatened region of NWA (Abdala $e t$ al. 2012; Giraudo et al. 2012). This incongruence in patterns of species richness between reptiles and other vertebrate groups (Powney et al. 2010) could be the main reason as to why the Gran Chaco ecoregion is poorly represented in priority areas for reptiles, and consequently why priority areas do not match geographically with the region where most conservation actions are needed (Hoyos et al. 2013; Frate et al. 2015; Nori et al. 2016a). For this particular political region, reptiles might not be the best taxon to use as a focal group for the selection of priority conservation areas. The selection of accurate focal groups is an essential step in conservation planning (Hermoso et al. 2013). More studies including and evaluating other taxa are needed in order to guide effective decisions about new PAs.

While our results pinpoint potentially important areas in order to efficiently expand the PA network in NWA, our analyses are limited mainly because of information shortfalls. Firstly, our database contained distributional records from
1980 up to the present date. Although we avoided areas with threatening human activities in the prioritization, predicted species distributions could be biased, given that some models were generated using old records from sites that are no longer inhabited. Other important limitations were the impossibility of generating SDMs for $50 \%$ of the included species (for which we considered no effect of climate change in their distributions), and the infeasibility of calibrating SDMs using distributional records from the entire ranges of some species (see Thuiller et al. 2004). The use of a single (intermediate) greenhouse gas concentration trajectory also meant that implementation of a different RCP could significantly alter our predictions of future distributions (Diniz-Filho et al. 2009).

Most priority areas identified in our study are located in the uplands. This result reflects the focus of the prioritization on the potential effects of climate change on species' distributions. In addition, in NWA, high-altitude areas and the species that are found there are the most exposed to climate change (Nori et al. 2016b) and many species are involved, including several endemics (Szumik et al. 2012). While climate and land-use changes jeopardize the existence of many species in NWA, comprehensive conservation planning is still needed. Using reptiles as a focal group is a first step, but more research and, especially, more political will is needed in order to advance the conservation agenda in the region.

\section{ACKNOWLEDGEMENTS}

We thank Town Peterson, two anonymous reviewers and Nicholas Polunin for their comments on the manuscript. JN and GCL's work was funded by FONCYT and SECYTUNC. RL's research has been constantly funded by CNPq (grants \#308532/2014-7, 479959/2013-7, 407094/20130 and 563621/2010-9), O Boticário Group Foundation for Nature Protection (grant \#PROG_0008_2013) and CNCFlora. This paper is a contribution of the Brazilian Network on Global Climate Change Research funded by $\mathrm{CNPq}$ (grant \#437167/2016-0) and FINEP (grant \#01.13.0353.00). RLP acknowledges the support of the Australian Research Council.

\section{Supplementary material}

For supplementary material accompanying this paper, visit https://doi.org/10.1017/S0376892917000285

\section{References}

Abdala, C.S., Acosta, J.L., Acosta, J.C., Álvarez, B.B., Avila, L.J., Blanco, G.M., Bonino, M., Boretto, J.M., Brancatelli, G., Breitman, M.F. et al. (2012) Categorización del estado de conservación de las lagartijas y anfisbenas de la República Argentina. Cuadernos de Herpetología 26: 215-247.

Araújo, M.B. \& New, M. (2007) Ensemble forecasting of species distributions. Trends in Ecology E Evolution 22: 42-47.

Balmford, A., Green, R. \& Phalan, B. (2012) What conservationists need to know about farming. Proceedings of the Royal Society B: Biological Sciences 279: 2714-2724. 
Barve, N., Barve, V., Jiménez-Valverde, A., Lira-Noriega, A., Maher, S.P., Peterson, A.T., Soberón, J. \& Villalobos, F. (2011) The crucial role of the accessible area in ecological niche modeling and species distribution modeling. Ecological Modelling 222: 18101819.

Brown, A., Martinez Ortiz, U., Acerbi, M. \& Corcuera, J. (2006) La Situación Ambiental Argentina. Buenos Aires, Argentina: Fundación Vida Silvestre Argentina.

Burkart, R. (2006) Las áreas protegidas de la Argentina. In: La Situación Ambiental Argentina, eds. A. Brown, A. Ortiz Martinez, M. Acerbi \& J. Corcuera, pp. 1-83. Buenos Aires, Argentina: Fundación Vida Silvestre Argentina.

Busby, J. (1991) BIOCLIM - a bioclimate analysis and prediction system. In: Nature Conservation: Cost Effective Biological Surveys and Data Analysis, eds. C.R. Margules \& M.P. Austin, pp. 64-68. Melbourne, Australia: CSIRO.

Carroll, C., Dunk, J.R. \& Moilanen, A. (2010) Optimizing resiliency of reserve networks to climate change: multispecies conservation planning in the Pacific Northwest, USA. Global Change Biology 16: 891-904.

CBI (2010) The Convention on Biological Diversity's 2010 Target [www document]. URL https://www.cbd.int/sp/targets/

Ciarleglio, M., Barnes, J.W. \& Sarkar, S. (2008) ConsNet - A tabu search approach to the spatially coherent conservation area network design problem. Fournal of Heuristics 16: 537557.

Ciarleglio, M., Wesley Barnes, J. \& Sarkar, S. (2009) ConsNet: new software for the selection of conservation area networks with spatial and multi-criteria analyses. Ecography 32: 205-209.

DeFries, R., Karanth, K.K. \& Pareeth, S. (2010) Interactions between protected areas and their surroundings in humandominated tropical landscapes. Biological Conservation 143: 28702880.

Devillers, R., Pressey, R.L., Grech, A., Kittinger, J.N., Edgar, G.J., Ward, T. \& Watson, R. (2015) Reinventing residual reserves in the sea: are we favouring ease of establishment over need for protection? Aquatic Conservation: Marine and Freshmater Ecosystems 25: 480-504.

Di Minin, E., Veach, V., Lehtomäki, J., Pouzols, F.M. \& Moilanen, A. (2014) A Quick Introduction to Zonation. Helsinki, Finland: Unigrafia OY.

Diniz-Filho, J.A.F., Bini, M.L., Rangel, F., Loyola, R.D., Hof, C., Nogues-Bravo, D. \& Araújo, M.B. (2009) Partitioning and mapping uncertainties in ensembles of forecasts of species turnover under climate change. Ecography 32: 897-906.

Faleiro, F.V. \& Loyola, R.D. (2013) Socioeconomic and political trade-offs in biodiversity conservation: a case study of the Cerrado Biodiversity Hotspot, Brazil. Diversity and Distributions 19: 977987.

Faleiro, F.V., Machado, R.B. \& Loyola, R.D. (2013) Defining spatial conservation priorities in the face of land-use and climate change. Biological Conservation 158: 248-257.

Franklin, J. (2009) Mapping Species Distributions New York, NY: Cambridge University Press.

Frate, L., Acosta, A.T.R., Cabido, M., Hoyos, L. \& Carranza, M.L. (2015) Temporal changes in forest contexts at multiple extents: three decades of fragmentation in the Gran Chaco (1979-2010), Central Argentina. PLoS ONE 10: e0142855.

Fuller, T., Sánchez-Cordero, V., Illoldi-Rangel, P., Linaje, M. \& Sarkar, S. (2007) The cost of postponing biodiversity conservation in Mexico. Biological Conservation 134: 593-600.
Garcia, R., Cabeza, M., Rahbek, C. \& Araújo, M.B. (2014) Multiple dimensions of climate change and their implications for biodiversity. Science 344: 1247579.

Gasparri, N.I. \& Grau, H.R. (2009) Deforestation and fragmentation of Chaco dry forest in NW Argentina (1972-2007). Forest Ecology and Management 258: 913-921.

Gibbons, J.W., Scott, D.E., Ryan, T.J., Buhlmann, K.A., Tuberville, T.E., Metts, B.S., Greene, J.L., Mills, T., Leiden, Y., Poppy, S. $\&$ Winne, C.T. (2000) The global decline of reptiles, déjà vu amphibians. Bioscience 50: 653-666.

Giraudo, A.R., Arzamendia, V., Bellini, G.P., Bessa, C.A., Cinthia, C., Cardozo, G., Chiaraviglio, M., Costanzo, M.B., Eduardo, G., Di Cola, V., Di Pietro, D.O. et al. (2012) Categorización del estado de conservación de las Serpientes de la República Argentina. Cuadernos de Herpetología 26: 303-326.

Grau, H.R., Torres, R., Gasparri, N.I., Blendinger, P.G., Marinaro, S. \& Macchi, L. (2015) Natural grasslands in the Chaco. A neglected ecosystem under threat by agriculture expansion and forest-oriented conservation policies. Fournal of Arid Environments 123: $40-46$.

Groves, C.R., Game, E.T., Anderson, M.G., Cross, M., Enquist, C., Ferdaña, Z., Girvetz, E., Gondor, A., Hall, K.R., Higgins, J. et al. (2012) Incorporating climate change into systematic conservation planning. Biodiversity and Conservation 21: 1651-1671.

Hermoso, V., Januchowski-Hartley, S.R. \& Pressey, R.L. (2013) When the suit does not fit biodiversity: loose surrogates compromise the achievement of conservation goals. Biological Conservation 159: 197-205.

Hoffmann, M., Hilton-Taylor, C., Angulo, A., Böhm, M., Brooks, T.M., Butchart, S.H.M., Carpenter, K.E., Chanson, J., Collen, B., Cox, N.A. et al. (2010) The impact of conservation on the status of the world's vertebrates. Science 330: 1503-1509.

Hoyos, L.E., Cingolani, A.M., Zak, M.R., Vaieretti, M.V., Gorla, D.E. \& Cabido, M.R. (2013) Deforestation and precipitation patterns in the arid Chaco forests of central Argentina. Applied Vegetation Science 16: 260-271.

IUCN \& UNEP (2015) The World Database of Protected Areas (WDPA). UNEP-WCMC. Cambridge, UK [www document]. URL www.protectedplanet.net

Kremen, C., Cameron, A., Moilanen, A., Phillips, S.J., Thomas, C.D., Beentje, H., Dransfield, J., Fisher, B.L., Glaw, F., Good, T.C. et al. (2008) Aligning conservation priorities across taxa in Madagascar with high-resolution planning tools. Science 320: 222 226.

Ladle, R.J. \& Whittaker, R.J. (2011) Conservation Biogeography. Chichester, UK: Wiley-Blackwell.

Laurance, W.F., Useche, D.C., Rendeiro, J., Kalka, M., Bradshaw, C.J., Sloan, S.P., Laurance, S.G., Campbell, M., Abernethy, K., Alvarez, P. et al. (2012) Averting biodiversity collapse in tropical forest protected areas. Nature 489: 290-294.

Lemes, P. \& Loyola, R.D. (2013) Accommodating species climateforced dispersal and uncertainties in spatial conservation planning. PLoS ONE 8: e54323.

Liu, C., White, M. \& Newell, G. (2011) Measuring and comparing the accuracy of species distribution models with presence-absence data. Ecography 34: 232-243.

Loyola, R.D., Lemes, P., Nabout, J.C., Trindade-Filho, J., Sagnori, M.D., Dobrovolski, R. \& Diniz-Filho, J.A.F. (2012) A straightforward conceptual approach for evaluating spatial conservation priorities under climate change. Biodiversity and Conservation 22: 483-495. 
Margules, C.R. \& Pressey, R.L. (2000) Systematic conservation planning. Nature 405: 243-253.

Mascia, M.B., Pailler, S., Krithivasan, R., Roshchanka, V., Burns, D., Mlotha, M.J., Murray, D.R. \& Peng, N. (2014) Protected area downgrading, downsizing, and degazettement (PADDD) in Africa, Asia, and Latin America and the Caribbean, 1900-2010. Biological Conservation 169: 355-361.

Merow, C., Smith, M.J., Edwards, T.C., Guisan, A., McMahon, S.M., Normand, S., Thuiller, W., Wüest, R.O., Zimmermann, N.E. \& Elith, J. (2014) What do we gain from simplicity versus complexity in species distribution models? Ecography 37: 12671281.

Moilanen, A., Anderson, B.J., Eigenbrod, F., Heinemeyer, A., Roy, D.B., Gillings, S., Armsworth, P.R., Gaston, K.J. \& Thomas, C.D. (2011) Balancing alternative land uses in conservation prioritization. Ecological Applications 21: 1419-1426.

Moilanen, A., Pouzols, F.M., Meller, L., Veach, V., Arponen, A., Leppänen, J. \& Kujala, H. (2014) Spatial Conservation Planning Methods and Software ZONATION. User Manual. Helsinki, Finland: C-BIG Conservation Biology Informatics Group, University of Helsinki.

Nori, J., Lescano, J.N., Illoldi-Rangel, P., Frutos, N., Cabrera, M.R. \& Leynaud, G.C. (2013) The conflict between agricultural expansion and priority conservation areas: making the right decisions before it is too late. Biological Conservation 159: 507 513.

Nori, J., Lemes, P., Urbina-Cardona, N., Baldo, D., Lescano, J. \& Loyola, R. (2015) Amphibian conservation, land-use changes and protected areas: a global overview. Biological Conservation 191: $367-374$.

Nori, J. \& Loyola, R. (2015) On the worrying fate of data deficient amphibians. PLoS ONE 10: e0125055.

Nori, J., Torres, R., Lescano, J.N., Cordier, J.M., Periago, M.E., \& Baldo, D. (2016a) Protected areas and spatial conservation priorities for endemic vertebrates of the Gran Chaco, one of the most threatened ecoregions of the world. Diversity and Distributions 22: 1212-1219.

Nori, J., Moreno Azócar, D.L., Cruz, F.B., Bonino, M.F. \& Leynaud, G.C. (2016b) Translating niche features: modelling differential exposure of Argentine reptiles to global climate change. Austral Ecology 41: 373-381.

Olson, D.M., Dinerstein, E., Wikramanayake, E.D., Burgess, N.D., George, V., Powell, N., Underwood, E.C., Jennifer, A.D., Itoua, I., Strand, H.E. et al. (2001) Terrestrial ecoregions of the world: a new map of life on earth. Bioscience 51: 933-938.

Phillips, S.J., Anderson, R.P. \& Schapire, R.E. (2006) Maximum entropy modeling of species geographic distributions. Ecological Modelling 190: 231-259.

Pimm, S.L., Jenkins, C.N., Abell, R., Brooks, T.M., Gittleman, J.L., Joppa, L.N., Raven, P.H., Roberts, C.M. \& Sexton, J.O. (2014) The biodiversity of species and their rates of extinction, distribution, and protection. Science 344: 1246752.

Pimm, S.L. \& Raven, P. (2000) Biodiversity. Extinction by numbers. Nature 403: 843-845.

Powney, G.D., Grenyer, R., Orme, C.D.L., Owens, I.P.F. \& Meiri, S. (2010) Hot, dry and different: Australian lizard richness is unlike that of mammals, amphibians and birds. Global Ecology and Biogeography 19: 386-396.

Pressey, R., Whish, G., Barrett, T. \& Watts, M. (2002) Effectiveness of protected areas in north-eastern New South Wales: recent trends in six measures. Biological Conservation 106: 57-69.
Pressey, R.L., Visconti, P. \& Ferraro, P.J. (2015) Making parks make a difference: poor alignment of policy, planning and management with protected-area impact, and ways forward. Philosophical Transactions of the Royal Society of London. Series B, Biological Sciences 370: 1-19.

Rangel, T.F. \& Loyola, R.D. (2012) Labeling ecological niche models. Natureza E Conservação 10: 119-126.

Rodrigues, A.S.L., Andelman, S.J., Bakarr, M.I., Boitani, L., Brooks, T.M., Cowling, R.M., Fishpool, L.D.C., Da Fonseca, G.A.B., Gaston, K.J., Hoffmann, M. et al. (2004) Effectiveness of the global protected area network in representing species diversity. Nature 428: 640-643.

Rodrigues, A.S.L., Brooks, T.M., Butchart, S.H.M., Chanson, J., Cox, N., Hoffmann, M. \& Stuart, S.N. (2014) Spatially explicit trends in the global conservation status of vertebrates. PLoS ONE 9: e113934.

Sarkar, S. \& Illoldi-Rangel, P. (2010) Systematic conservation planning: an updated protocol. Natureza Conservação 8: 19 26.

Schneider, A., Friedl, M. \& Potere, D. (2009) A new map of global urban extent from MODIS satellite data. Environmental Research Letters 4: 044003.

Sinervo, B., Méndez-de-la-Cruz, F., Miles, D.B., Heulin, B., Bastiaans, E., Villagrán-Santa Cruz, M., Lara-Resendiz, R., Martínez-Méndez, N., Calderón-Espinosa, M.L., Meza-Lázaro, R.N. et al. (2010) Erosion of lizard diversity by climate change and altered thermal niches. Science 328: 894-899.

Szumik, C., Aagesen, L., Casagranda, D., Arzamendia, V., Baldo, D., Claps, L.E., Cuezzo, F., Diaz Gomez, J.M., Di Giacomo, A. et al. (2012) Detecting areas of endemism with a taxonomically diverse data set: plants, mammals, reptiles, amphibians, birds, and insects from Argentina. Cladistics 28: 317-329.

Thuiller, A.W., Georges, D. \& Engler, R. (2013) Package 'biomod2' [www document]. URL http://cran.r-project.org/ web/packages/biomod2/index.html

Thuiller, W., Brotons, L., Araujo, M.B. \& Lavorel, S. (2004) Effects of restricting environmental range of data to project current and future species distributions. Ecography 27: 165-172.

Torres, R., Gasparri, N.I., Blendinger, P.G. \& Grau, H.R. (2014) Land-use and land-cover effects on regional biodiversity distribution in a subtropical dry forest: a hierarchical integrative multi-taxa study. Regional Environmental Change 14: 15491561.

Varela, S., Mateo, R.G., García-Valdés, R. \& Fernández-González, F. (2014) Macroecología y ecoinformática: sesgos, errores y predicciones en el modelado de distribuciones. Ecosistemas 23: 46-53.

Venter, O., Fuller R., A., Segan, D.B., Carwardine, J., Brooks, T., Butchart, S.H.M., Di Marco, M., Iwamura, T., Joseph, L., O'Grady, D. et al. (2014) Targeting global protected area expansion for imperiled biodiversity. PLoS Biology 12: e1001891.

Volante, J.N., Mosciaro, M.J., Gavier-Pizarro, G.I. \& Paruelo, J.M. (2016) Agricultural expansion in the Semiarid Chaco: poorly selective contagious advance. Land Use Policy 55: 154-165.

Watson, J.E.M., Dudley, N., Segan, D.B. \& Hockings, M. (2014) The performance and potential of protected areas. Nature 515: 67-73.

Woodley, S., Bertzky, B. \& Crawhall, N. (2012) Meeting Aichi Target 11: what does success look like for protected area systems. Parks, the International Journal of Protected Areas and Conservation 18: 23-36. 